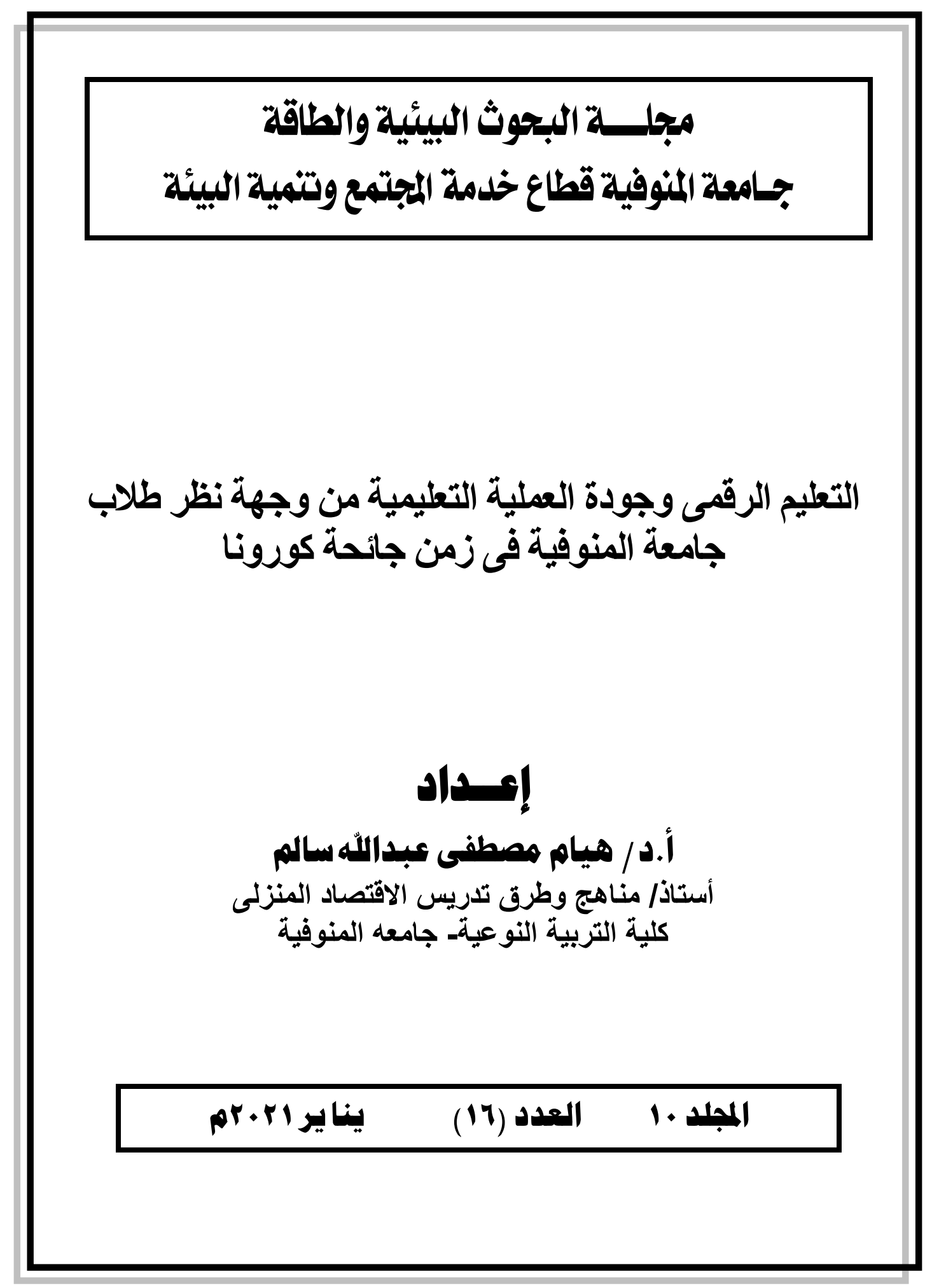




\title{
التعليم الرقمى وجودة العملية التعليمية من وجهة نظر طلاب جامعة المنوفية فى زمن جائحة كورونا
}

\author{
أ.د/ هيام مصطفى عبدالله سالم

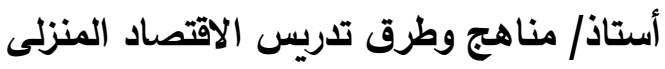 \\ كلية التربية النوعية- جامعه المنوفية
}

مقدمة :

نتيجة للتطور السريع فى تكنولوجيا التعليم فى العقديين الماضيين فقد ظهر عنه إنتاج وسائط

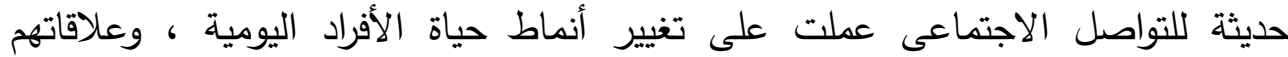

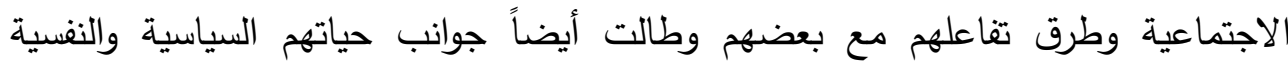
والاقتصادية والصحية والتربوية , و هذا ما افرز في المقابل ضرورة تطوير و تحديث مختلف البيئات التعليمية إن التطور التكنولوجي الحاصل ادخل قفزة نوعية ايجابية كبيرة في

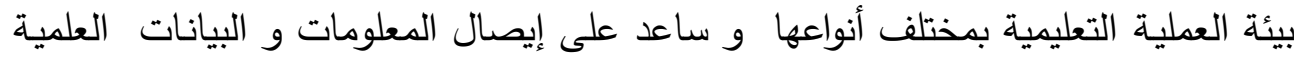
التربوية وحتى السلوكية للفرد الدتعلم و ذلك من خلال اعتماد أسلوب التعلم الرقمي أو الو التهاعل

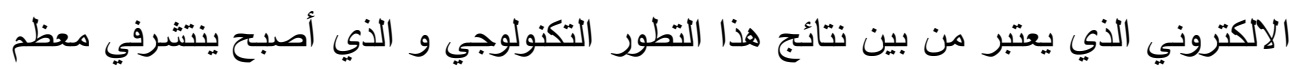

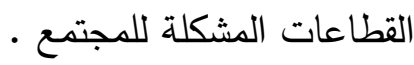
ومر التعليم العالي في مصر بأزمة حادة مع مطلع القرن العشرين نتيجة التئي التياح وباء

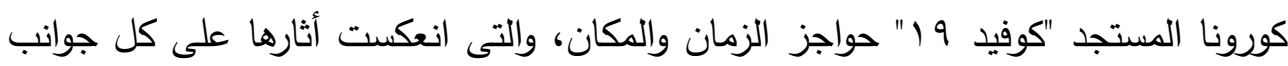
الحياة خاصتنا التعليم ،حيث تم إغلاق الددارس والجامعات كأجراءات احترازية للوقاية من التئان

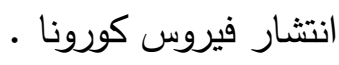

لذا واجهت مؤسسات التعليم العالى تحدى تحسين جودة عمليتها التعليمية بعناصرها المختلفة

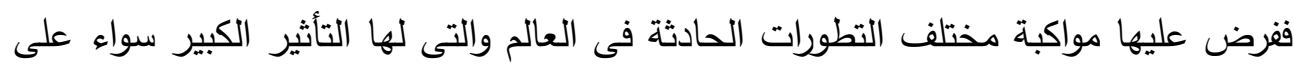

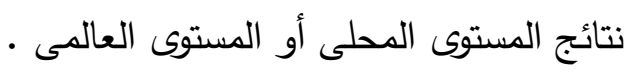


لذا أصبح من الضرورى مواجهة هذا التحدى والتصدى له من خلال الطرق والاساليب

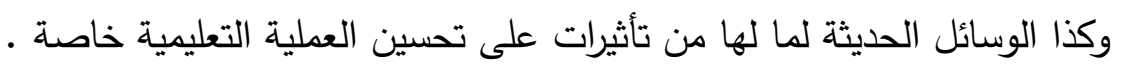
ونظراً لأنتا نعيش اليوم عصر التطور الهائل للوسائل التكنولوجية ، فنتج عن هذائل التهائه التطور

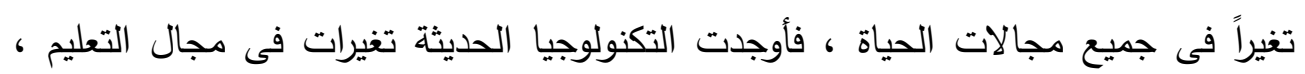
حيث تغيرت أهدافه ومجالاته وطرق وأساليبه وظهرت مصطلحات ومسميات جديدة لطرق التعلم الحديث منها : التعلم الاككترونى والتعلم المباشر والتعلم عن بعد وغيرها ، وجميعها

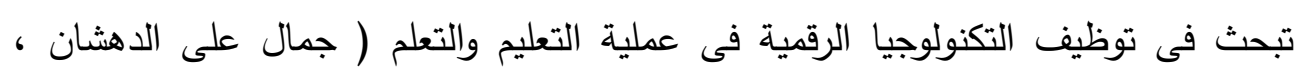
$(r \cdot v$

وبما أن الاتجاهات الحديثة فى التدريس بصورة عامة تدعو إلى ترك الأساليب التقليدية

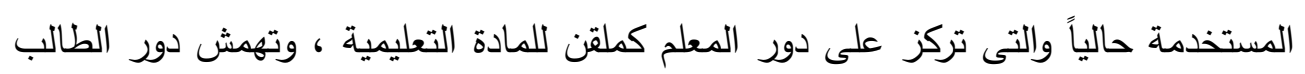
وتحد من تفاعله داخل غرفة التعلم وخارجه ، وبالتالى لا تؤدى الغرض المنشود فى تحقيق دورة الاهداف التربوية والمعرفية والمهارية والوجدانية وتحقيق التعلم الفعال.

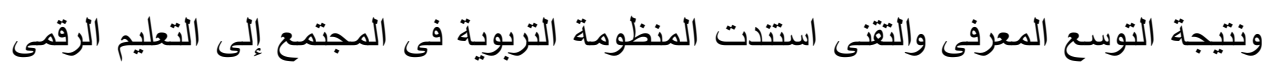

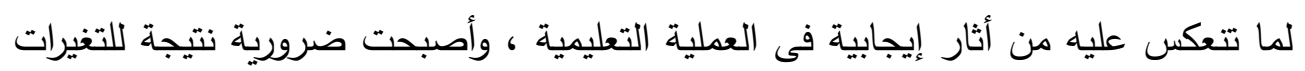
الاجتماعية والتكنولوجيا الحديثة . التعليم الرقمى ، تطبيقات واستراتيجيات والتعلم الاكترونى الحديث ، الموقع الاكترونى https://sites.google.com/site/learningandteachingstrategies1/h أقبلوا المدتعلمين بشكل كبير على استخدام التكنولوجيا في حياتهم وأصبحت تأخذ كل وقته ، فهي ببيئة متطورة وفاعلة يمكن أن تستخدم التكنولوجيا الحديثة وتعمل على دمجها

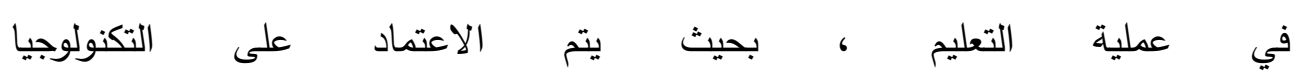

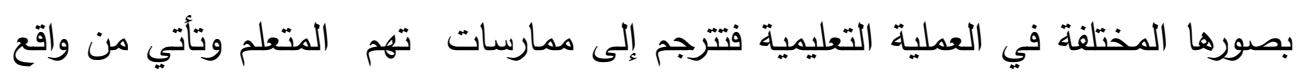
بيئته ، وتعزز التكنولوجيا أيضاً ممارسات تعتمد على الحوار وإشراك المتعلم في سياقات مثيرة للإهتمام مثل التعلم بالاكتشاف وإدخال مهارة حل المشكلات ومهارات القيادة.. 
وتعد الأجهزة الإكترونية أحد أهم المستحدثات التكنولوجية العالمية فى عصرنا الحالى ، وتجسد تكنولوجيا التعلم الرقمى موضوعاً هاماً ومحوراً لاهتمام الفكر التربوى والمادة الثاغلة للعديد من البحوث والدراسات فى مجال تطوير البيئة التعليمية بصفة عامة والبيئة الجامعية بصفة خاصة ، كونها التكنولوجيا الأكثر كفاءة ومرونة لاستخدام أنواع مختلفة من الأنشطة

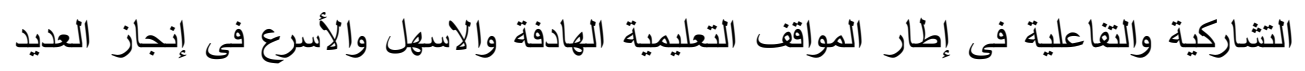
من الأعمال ، مما يعمل على خلق بيئات تعليمية غنية ، تثرى متطلبات الأفراد وتلبى التهات

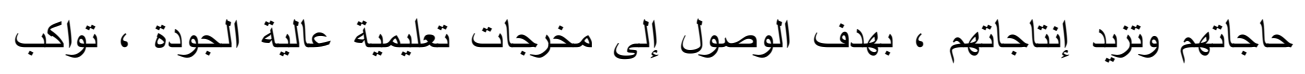
مستحدثات العصر وتحقق متطلبات المرحلة الراهنة، إن القيمة التى يضيفها التعلم الرقمى على العملية التعليمية تشمل جانبين : - الجانب المعرفى : المتمثل فى إتقان مهارات القراءة والكتابة ومهارات البحث هيث - الجانب التربوى : المتمثل فى تغيير السلوك واكتساب مهارات الحياة وتتمية الحافز للتعلم فهو فى مجملة ترجمة حقيقية وعملية لفلسفة التعليم عن بعد التى تقوم على توسيع قاعدة الفرص التعليمية أمام الأفرراد ، وتخفيض كلفتها بالمقارنة مع نظم التعليم التقليدية ، وأغتتام

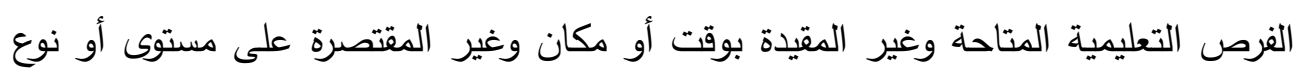
معين من التعليم ، حيث يتابع المتعلم تعلمه حسب طاقته وقدرته وسرعة تعلمه ووفقاً لما

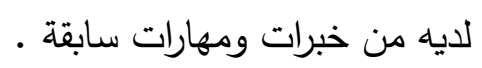
أن توظيف كل ماهو جديد فى ميادين التربية والتعليم ، من أجل تطوير أنظمتها وتفعيل مدخلاتها للقيام بدورها الوظيفى لخدمة الأفراد والمجتمع ، ورفع وتطوير أساليب التعلم والتدريس بإستخدام أنواع مختلفة من الأنشطة فى إطار المواقف التعليمية الهادفة التى تقوم

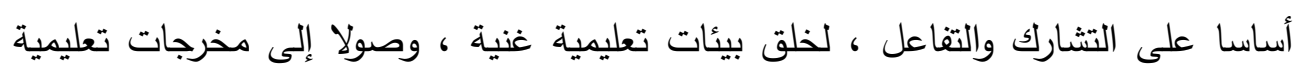
عالية الجودة. - ماستا من هنا قامت الباحثة بدراسة واقع منظومة التعلم الرقمي فى جامعة المنوفية ، في ظل مانل

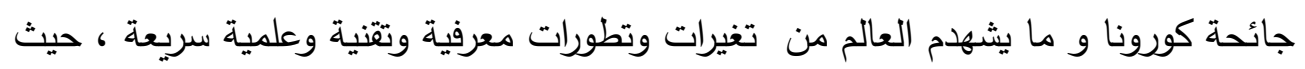

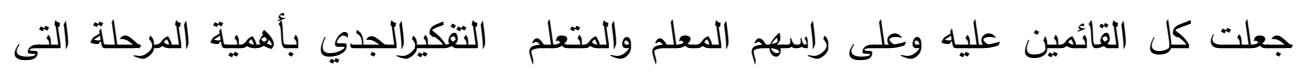


يمربها التعليم ،كي يكونوا مؤهلين وقادريين على التعامل مع هذه الدستحدثات التقنية بدرجة

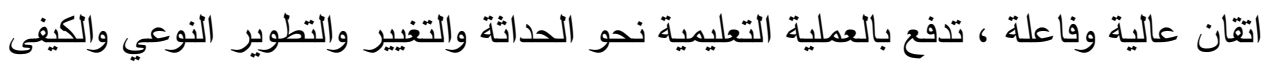

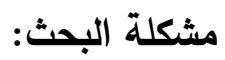
انطلاقا من سعى الدولة نتيجة إنتثار وباء كورونا المستجد "كوفيد 9 ا" وما تركه من أثار

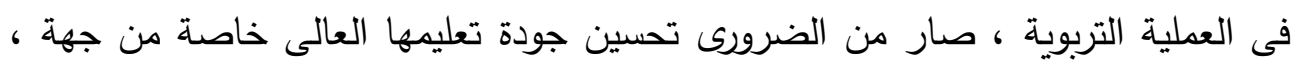

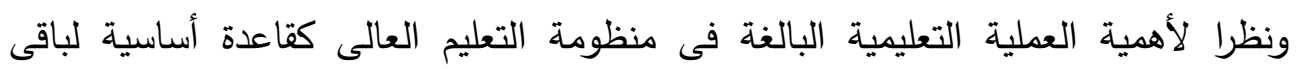

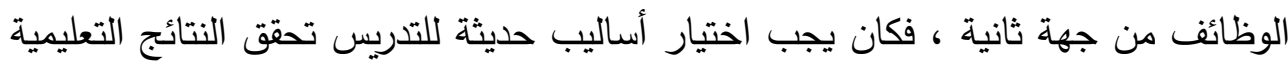
المستهدفة ، ونظراً للتطور التكنولوجي الذى ادخل قفزة نوانبة نوعية إيجابية في بيئة العملية

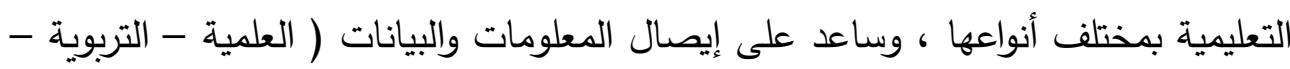

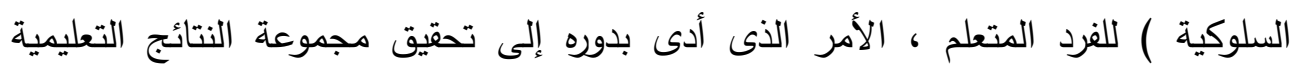

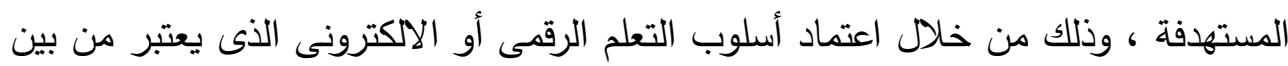

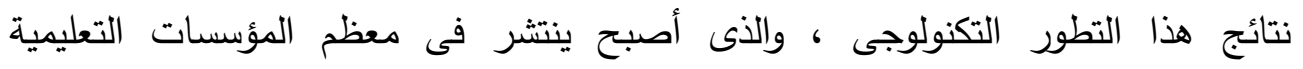
والقطاعات المشكلة للمجتمع.

\section{وفى ضوء ما سبق تبلورت مشكلة البحث فى السؤال الرئيس التالى؟}

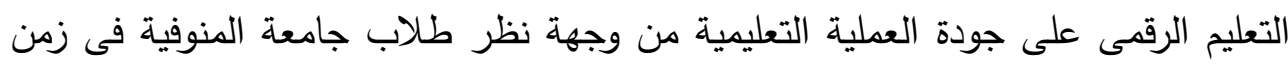

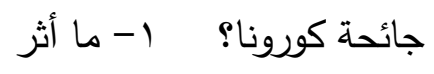

r- - ما معوقات تطبيق التعليم الرقمى فى جامعة المنوفية من وجهة نظر الطلاب بجامعة

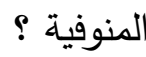

$$
\text { أهمية البحث: تكمن أهمية البحث فى : }
$$

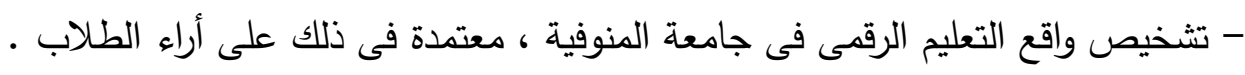

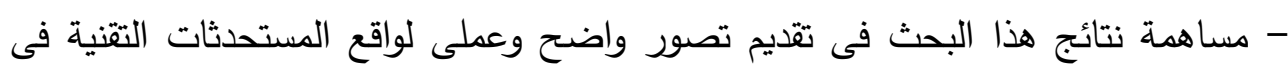

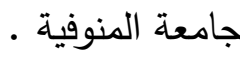
- تطوير التعليم باستخدام التثنية فى العملية التعليمية ، بهدف تحقيق تعليم أفضل على العية

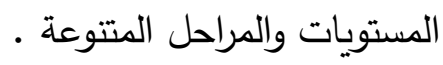

191

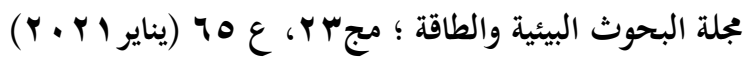


- تحسين الواقع الراهن لاستخدامات التعليم الرقمى وتطويره. - حصر المعيقات التى تحول دون الاستخدام الفعال للتعلم الرقمى فى العملية التعليمية.

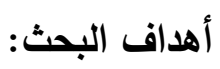

\section{تنبع أهمية البحث إلىى:}

التعليم الرقمى على جودة العملية التعليمية من وجهة نظر طلاب جامعة المنوفية فى زمن

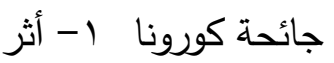
r- التعرف على معيقات تطبيق التعليم الرقمى فى جامعة المنوفية من وجهة نظر الطلاب فى زمن جائحة كورونا. حدود البحث:

- الحدود الموضوعية : اقتصر البحث على دراسة واقع التعليم الرقمى فى جامعة المنوفية من حيث( جودة العملية التعليمية- معوقات تطبيقة ).

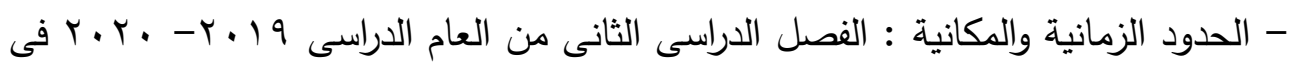
جامعة المنوفية . الحدود البشرية : اقتصر البحث على عينة عشوائية من طلاب السنة الرابعة بكليات جامعة المنوفية

$$
\text { • مصطلحات البحث: }
$$

\section{- Digital Learning مفهوم التعليم الرقمى -}

تعرفه الباحثة إجرائياً: بأنه تقديم محتوى تعليمى عبر الوسائل المعتمدة على الأجهزة الإلكترونية إلى المتعلم بشكل يتيح التعليم و يحقق فورية الاتصال بين الطلاب والمدرسين إلكترونياً، سواء كان ذلك بصورة متزامنة أم غير متزامنة من خلال شبكة أو شبكات إلكترونية حيث تصبح المدرسة أو الكلية مؤسسة

$$
\text { شبكية من هن }
$$

\section{- مفهوم الجودة -}


تعرفها الباحثة إجرائياً: بأنها تعنى عملية التوظيف الجيد والمتكامل والمتزن

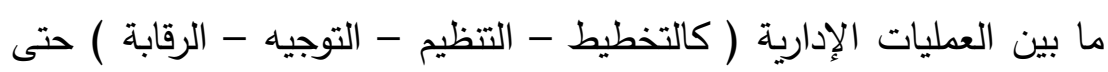

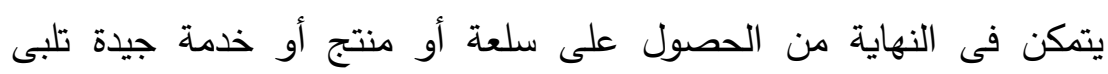

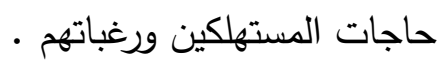

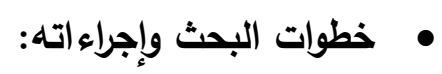

أولا: تحديد فقرات استبيانات من حيث ( الإيجابية - المعوقات) للطلاب .

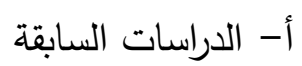

ب- الأدبيات التى تتحدث عن التعليم الرقمى - من وجهة نظر (الطلاب)

$$
\text { ت- ت - رأى المتخصصين - الخبراء. }
$$

ثانياً: وضع الأسس التى بنيت عليها استيبانه (الطلاب) لقياس رأيهم فى التعليم الرقمى وجودة العملية التعليمية وذلك من خلال:

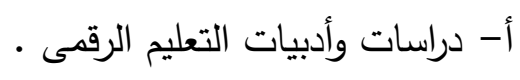

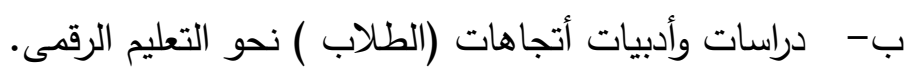

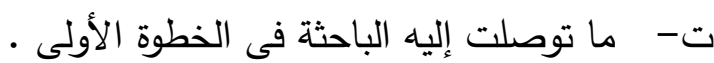

ثالثاً: إعداد الاستبانة الخاصة بالطلاب.

$$
\text { رابعاً: تطبيق الاستبانة وتتطلب: }
$$

ب- إعداد الاستبيانات إلكترونيا الخاصة بالطلاب ، للتعرف على وجهات نظرهم فى التى

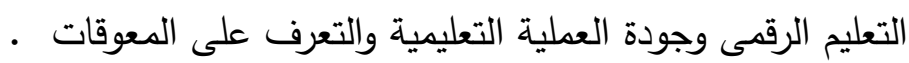

$$
\text { ث- النتائج • النبيق · }
$$

الإطار النظرى للبحث والاراسات السابقة:

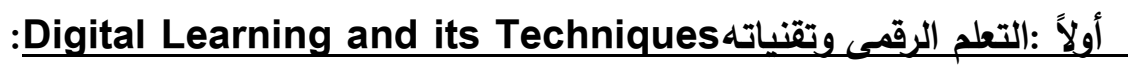


التعلم الرقمى يشكل معضلة كبيرة عندما يتعلق الأمر بضمان جودة التعليم ، كما أن

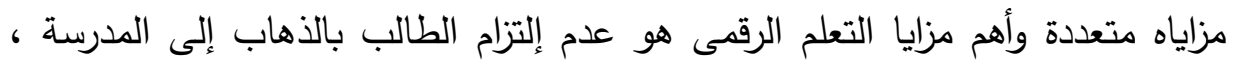

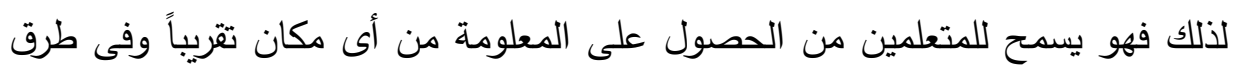
جديدة ومتعددة ، وهذا ما ساعدنا فى ظل جائحة كورونا من تحقيق النتائج التعليمية المستهدفة والتعلم الرقىى يكون فعال إذا توفر شرطان أساسيان هما : - التعرف على تكنولوجيات التعلم والمهارات التقنية والتكنولوجية. - توفير بيئة تعليمية جديدة من التعلم عن طريق التعلم الذاتى .

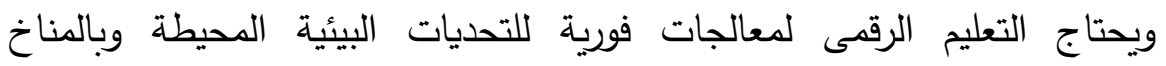
التتظيمى للمؤسسة التعليمية ، كما يضم التعليم الرقمى المكونات الإكترونية التالية : الكتاب الإلكترونى ، الامتحانات الإلكترونية ، عرض النتائج والدرجات إلكترونيا .

\section{1- تعريف التعلم الرقمي Definition of Digital Learning:}

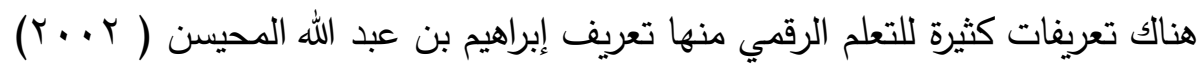
للتعليم الر قمى على أنه : ذلك الك التهب التعليم الذي يعتمد على استخدام الوسائط الالكترونية في الاتصال بين المعلمين و المتعلمين و المؤسسة التعليمية برمتها

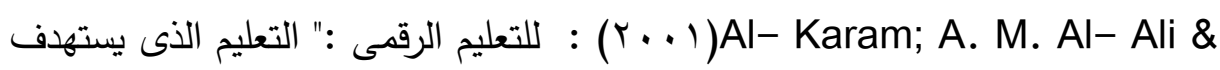
N. M يعرف كلا من إيجاد بيئة تفاعلية غنية بالتطبيقات المعتمدة على تقنيات الحاسب الآلي والإنترنت وتمكن الطالب من الوصول إلى مصادر التعلم في أي وقت ومن أي مكان"

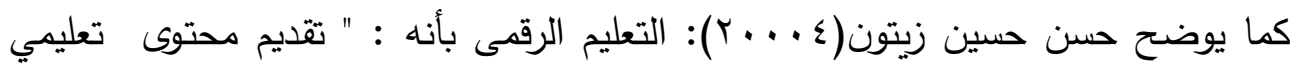

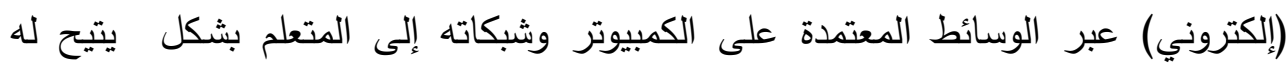

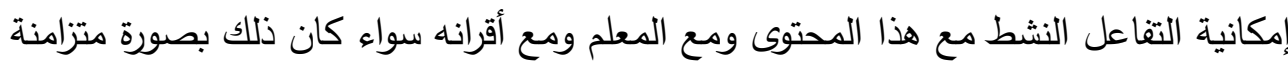

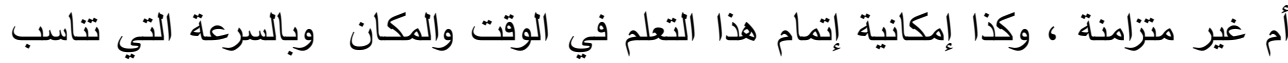
ظروفه وقدراته، فضلاً عن إمكانية إدارة هذا التعلم أيضاً من خلال تلك الوسائط التط 
r أ- التعلم الرقمي المباشر : و الذي يتمثل في تلك الأساليب و التقنيات التعليمية المعتمدة

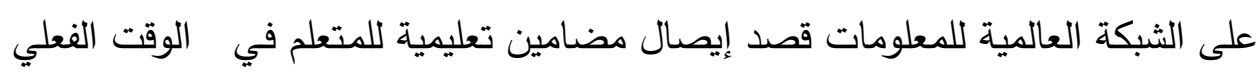
و الممارس للتعليم أو التدريب(القسم ، المصنع) •

ب- التعلم الرقمي غير المباشر : و هو الذي يتمثل في عملية التعلم من خلال مجموعة التمات

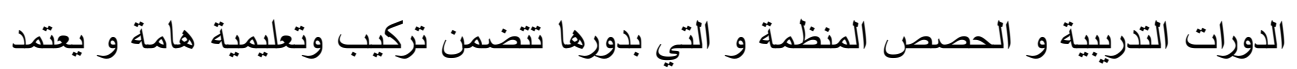
هذا النوع من التعلم الرقمي بالنسبة لحالة وجود ظروف متعددة لا تسمح بالحضور الفعلي للفرد المتعلم(التلميذ في المدرسة ، الجامعة ، العامل في البيئة المهنية)

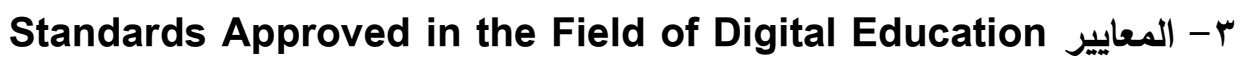
المعتمدة في مجال التعليم الرقمي يعتبر التعلم الرقمي من أهم الأساليب الحيوية المعتمدة في عملية التعلم بشكل عام خاصة

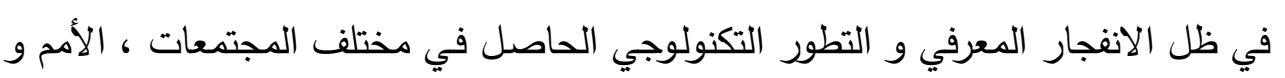
بالإضافة إلى هذا ، نجد أن التعلم الرقمي يعمل على ارتفاع معدلات القبول في التعلم بشكل عام و الإقدام على طلبه ، تدريب ، تعليم العمال و تأهيلهم و تحسين أدائهم في البيئة المهنية. وفى هذا الإطار نجد أن معهد التدريب لتقنية المعلومات قام بتطوير معايير أساسية للتعلم الرقمي أو الاككتروني في العديد من المحاور كدعم عملية التعلم صميم التعليم و محتواه ،

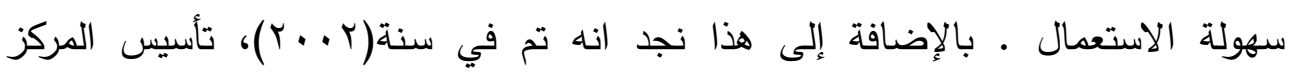

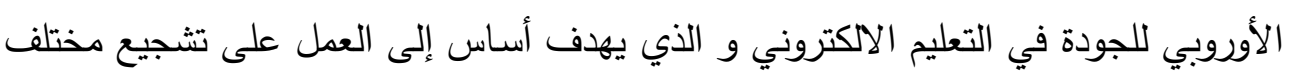

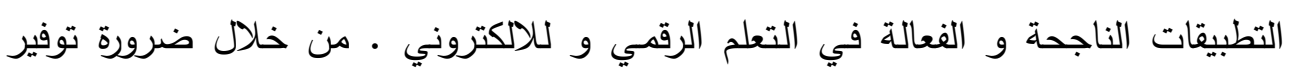
جميع التوجيهات ، الدعم و الخدمات المناسبة للتقويم المستمر لخدمات هذا النوع من التعلم في بيئات تعلم تتميز بالتغير و الحركية الدائمة

ع - أهداف التعليم الرقمي: Digital Education Goals :

-القدرة على تلبية حاجات و رغبات المتعلمين المعرفية و العلميةه

$r \cdot r$

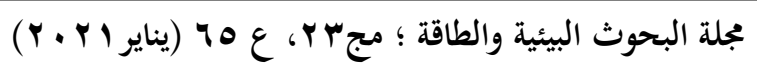


- تحسين عملية الاحتفاظ بالمعلومات المكتسبة و الوصول إليها في الوقت المناسب سرعة تجديد المعلومات و المعارف و ترتيبها حسب أهميتها و الموقف المعاش. تحسين التفاعل و التعامل بين طرفي العملية التعليمية ( المعلم - الطالب ) -

ه- خصائص التعلم الرقمى:Characteristics of Digital Learning: حسب الاتحاد الأمريكي للتعليم عن بعد نجد من خصائص التعليم الرقيي مايلي: 1- دعيم عملية تكوين الفرد و توفير الاتصال و التفاعل المتبادل.

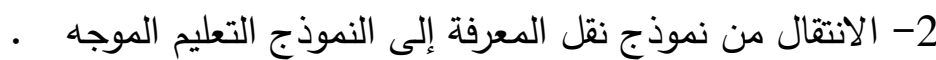
r- تشجيع المشاركة الديناميكية و الحيوية للمتعلم. 4- الاعتماد على المهارات و بالخصوص في شقها التفكيري العالي. 0- توفير مستويات متعددة من التفاعل و تشجيع التعليم النشط.

\section{ثانياً : تعريف الجودة وأهميتها Definition of Quality and its Importance:}

تعتبر مؤسسات التعليم العالى من المؤسسات الخدمية التى تصبو إلى تحسين جودة تعليمها

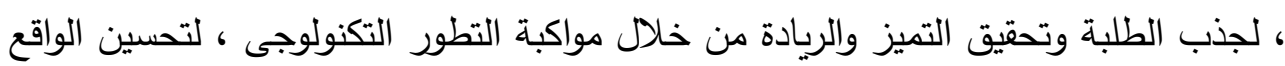
ومتطلباته لتطوير المعارف ، المفاهيم ، العادات ، القيم ، الاتجاهات ومواكبة التقدم العلمى

$$
\begin{array}{r}
\text { الذى يسير بخطوات متسارعة. } \\
\text { Quality }
\end{array}
$$

عرفها المعهد الوطنى الامريكى للمقاييس والجمعية الامريكية لمراقبة الجودة بانها " مجموعة من السمات والخصائص للسلع والخدمات القادرة على تلبية احتياجات محددة " بينما عرفها معهد الجودة الفيدرالى الامريكى انها "اداء العمل الصحيح بالشكل الصحيح من

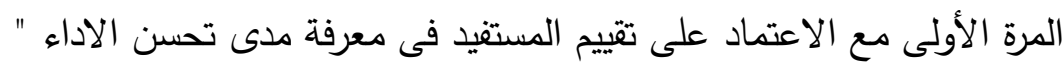
ومن منظور العملية التعليمية فالجودة تعنى " الوصول الى مستوى الاداء الجيد وهى تمثل عبارات سلوكية تصف اداء المتعلم عقب مرورة بخبرات منهج معين ويتوقع ان يستوف مستوى تمكن محدد مسبقاً " 
التعليم الرقمى وجودة العملية التعليمية من وجهة نظر طلاب جامعة المنوفية فى زمن جائحة كورونا

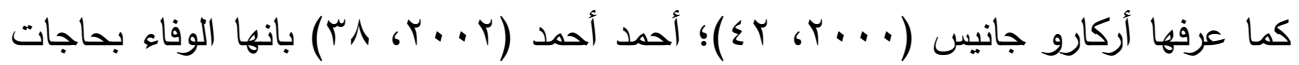
المستفيد حاليا ومستقبلا كما تعرف بانها مدى قدرة المؤسسة على العمل بما يتتاسب مع اهع الاهداف المنشودة.

* فى ضوء ما سبق تعرف الباحثة الجودة فى العملية التعليمية إجرائياً بأنها مجموعة من الخصائص والسمات التى تساعد كل من المعلم والمتعلم على الآداء الجيد بهدف الوصول بالمتعلم إلى درجة الإتقان بعد مروره بخبرات تعليمية معينة مع توفير وقت وجها المعلم.

ب - Definition of Higher Education Quality تعريف جودة التعليم العالى تمثل الجودة بشكل عام احد المتطلبات الرئيسية للتعليم العالي والجامعات المعاصرة في الوقت الراهن، إذ تزايد الاهتمام بجودة التعليم العالي عالميا ومحليا في الآونة الأخيرة وتزايدت معه جهود إيجاد معايير هذه الجودة؛ لما لذلك من أهمية في تحسين مخرجات هذا القطاع، وتأهيل خريجيه للمنافسة في ميادين العمل المختلفة وفق معايير دولية. وبالتالي تم التوجه من طرف كل الدول نحو تحسين جودة تعليمها للرقي والنمو باقتصادياتها فقد أصبحت جودة التعليم العالي رهان العصر الحالي إذ تعني:

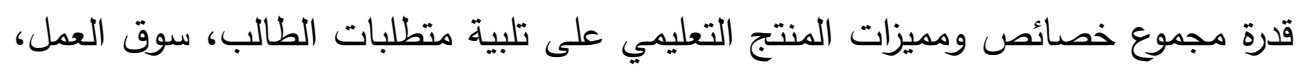
المجتمع وكافة الجهات الداخلية والخارجية المنتفعة. مع أن تحقيق جودة التعليم العالي يتطلب توجيه كل الموارد البشرية، السياسات، النظم، المناهج، العمليات والبنية التحتية من وده اجل خلق ظروف مواتية للابتكار والإبداع في ضمان تلبية المنتج التعليمي للمتطلبات التي تهيئ الطالب لبلوغ المستوى الذي نسعى جميعا لبلوغه.( يوسف الطائى وأخرون ، 1 ... r،

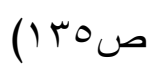

ب - مفهوم الجودة Quality:

مع تطور الفكر التربوى وظهور مفهوم الجودة ازداد اهتمام الكتاب والباحثين بموضوع جودة

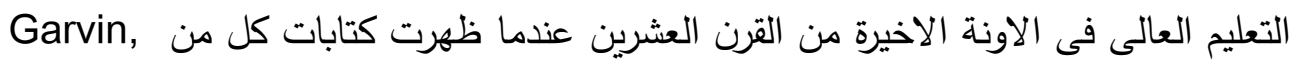


Juran, Crosby, Deming

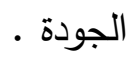

فقد عرف دينج ( Deming, 1986, 11-17) الجودة فى قطاع التعليم بانها :" عملية

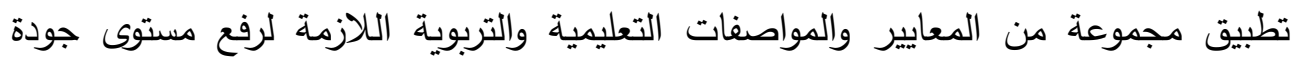

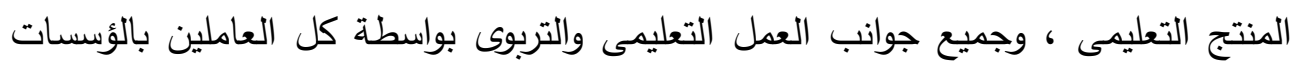
التعليمية "

وعرفها شينج (Cheng(1996 بانها " مجموعة عناصر لابد ان تتوفر فى المؤسسات التعليمية بما تتضمنه من مدخلات ، وعمليات، ومخرجات تلبى احتياجات الاطراف المعنية من خلال تحقيق توقعاتهم الصريحة والضمنية .

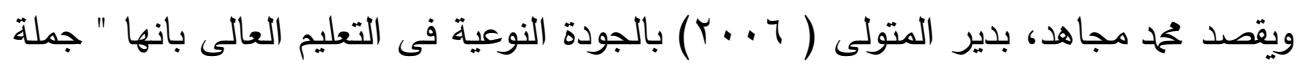
الخصائص والمعايير التى ينبغى ان تتوفر فى جميع عناصر العملية التعليمية ، سواء فيما

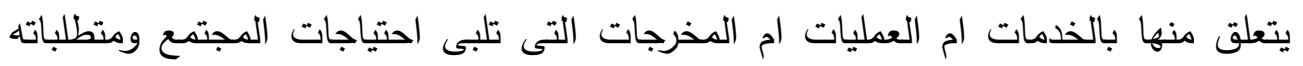
ورغبات المتعمين وحاجاتهم وتتحقق من خلال الاستخدام الفعال لجميع العناصر البشرية والمادية با لمؤسسة التعليمية. وتعتبر الجودة احد أهم الوسائل والأساليب لتحسين نوعية التعليم والارتقاء بمستوى أدائه في

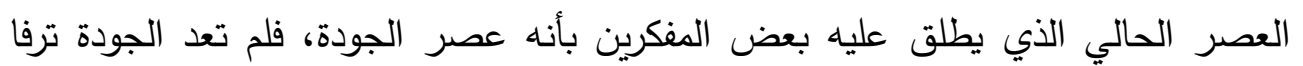
ترنو إليه المؤسسات التعليمية او بديلا تأخذ به او تتركه الأنظمة التعليمية ، بل أصبح بلانه ضرورة ملحة تمليها حركة الحياة المعاصرة . ويمكن القول: إن الجودة في التعليم تعني كما يشير راتب السعود (Y . . ب) قدرة المؤسسة التربوية على تقديم خدمة بمستوى عال من الجودة المتميزة، وتستطيع من خلالها الوفاء

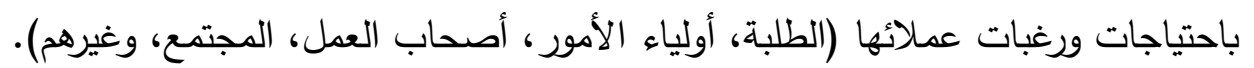

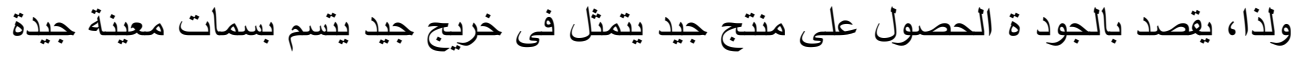

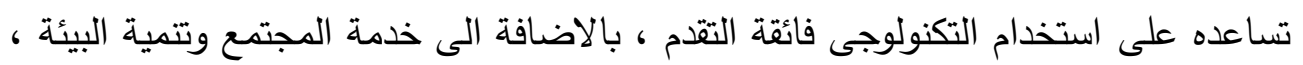
من خلال تحسين مدخلات العملية التعليمية التى تتضمن مداخل وطرائق واساليب 
التدريسوخاصة استخدام التعلم الذاتى والاسهام فى انتاج المعرفة اكثر من مجرد تلقى المعرفة ، مع توفير مصادر المعرفة ومراكز المعلومات والاهتمام بالتطبيقات العملية والميدانية

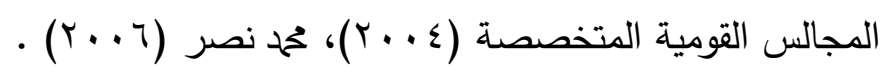

\section{Stages of Quality Development - مراحل تطوير الجودة}

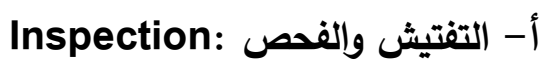

منذ بداية الستينات من هذا القرن كان التركيز فى ادارة الجودة منصباً على تفتيش

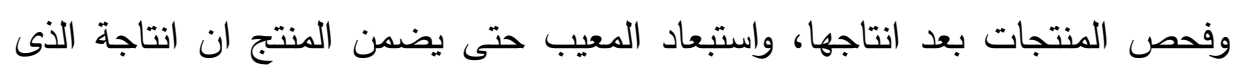
يقدمه للمستفيد لا توجد به عيوب ، وللتاكد من مدى مطابقة المنتجات للمواصفات

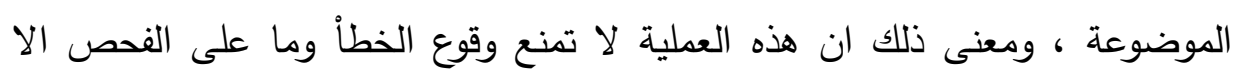

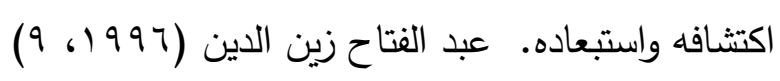

بuality Control : بواقبة الجودئ

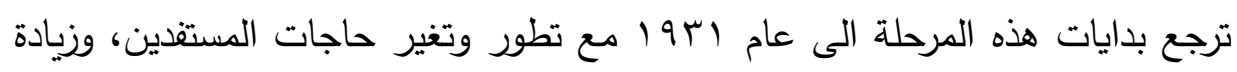
حدة المنافسة لم بعد مفهوم التفتيش والفحص ملائماً وبالتالى كانت الحاجة ماسة لظهئ لظهور مفهوم جديد يساهم فى تحقيق مستويات الجودة المطلوبة وادارتها بطريقة سليمة وهو ما ادى الى ظهور مدخل مراقبة الجودة ويقصد بمراقبة الجودة " مجموعة من العمليات

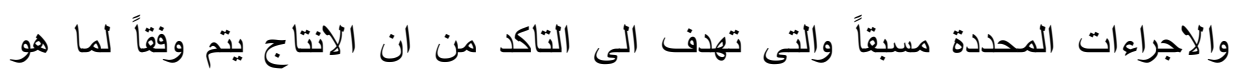
مطلوب لتحقيق مستوى الجودة المرغوبة " ويتم ذلك من خلال الخطوات التالية : - - مضع مجموعة من المقاييس او المعايير لمقابلة المواصفات المطلوبة للجودة . - - اختبار وفحص المنتج النهائى للتاكد من تحقيقه مواصفات الجودة . - اكتشاف الانحرافات واتخاذ الاجراءات التصحيحية . - - التخطيط للتحسين المستمر للجودة . 
ج- تاكيد الجودة فى العملية التعليميه: Quality Assurance

مع بداية فترة السبعينات تحول مفهوم الجودة الى مفهوم منع وقوع الاخطاء ويعنى ذلك ان الجودة " تبنى من البداية وقبل البدء فى العملية الانتاجية فهى تظهر فى مرحلة

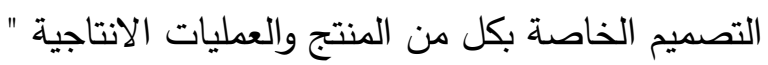

وتاكيد الجودة يثمل عمليات التخطيط وتحسين تصميم المؤسسة وتطوير الرقابة على ونى

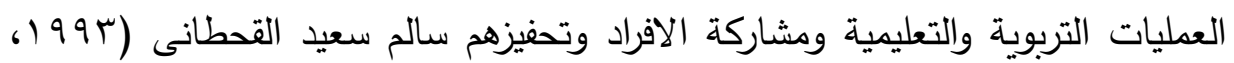

مeasons for Apphying Quality دواعى تطبيق الجودة فى العملية التعليمية in the Educational Process

فى السنوات القليلة الماضية لوحظ ان غالبية الدول النامية اخذت باستراتيجية الكم لاستيعاب الأعداد الكبيرة من الطلاب فى العملية التعليمية وأدى ذلك إلى التضحية

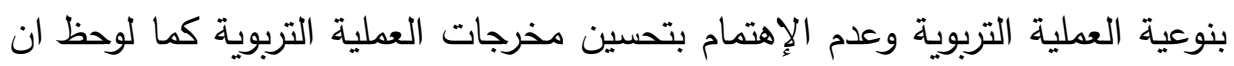
الثورة التكنولوجية الهائلة والقائمة على ثورة المعلومات والمعرفة لا يمكن مواكبتها بالطرائق التقليدية فى العملية التعليمية وبما ان الطالب هدف ومحور العملية فيجب ارضائه كفرد اساسى فى العملية التربوية لهذه الأسباب كان من الضرورى اجراء التحسينات فى العملية التربوية بطريقة منظمة وخلق الاتصال الفعال على المستويين الافقى والعمودى ولا يمكن تحقيق ذلك إلا من خلال تطوير الاداء التدريسى للمعلم بتطبيق الجودة فى العملية التعليمية

The Teacher’s Role in Achieving - دور المعلم فى تحقيق جوده التدريس : Teaching Quality بالنظر الى التدريس باعتباره شيئا، والى المعلم باعتباره انساناً يستخدم هذا الثىء ويحركه ويجوده فاننا نقرر ان جودة التدريس واصالته لا يمكن ان تتحقق الا بتحقيقها

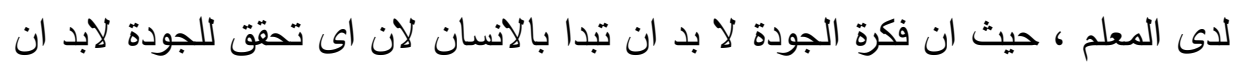

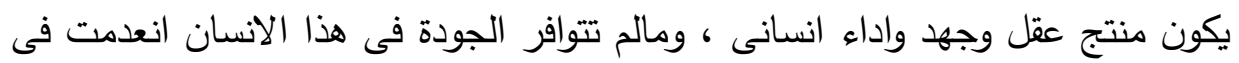


غيره سواء اكان هذا الغير منتجاً مادياً اى (شىء) او منتجاً بشرياً اى ( انسان ) ، وفى هذا السياق ينبغى ان يوفر المعلم للتدريس اداء يستوفى الجودة . وبتطوير الاداء التدريسى سوف يرتكز التعليم على أنماط التدريس الفعال، ونوعية ذلك التعليم يحدد فاعليتها مهارة المعلم وبراعته في تهيئة المناخ التدريسي للتعلم، وخلق الإثارة العقلية لدى طلابه، والتواصل الإيجابي فيما بينه وبينهم، بالإضافة إلى طبيعة العلاقات التي قد تساعد في استثارة دافعيتهم وبذل قصارى مالديهح من قدرات في سبيل

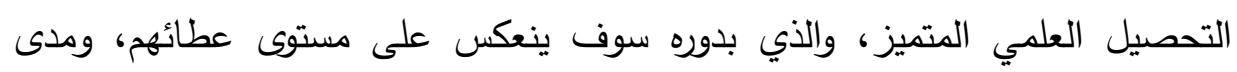

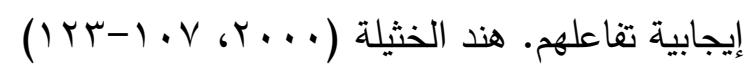
ان التركيز على تطوير الاداء التدريسى وفق معايير الجودة فى التعليم يعنى جودة منتج وهو لدينا انسان لابد ان يستوفى الشروط والمواصفات القياسية للجودة الاصيلة

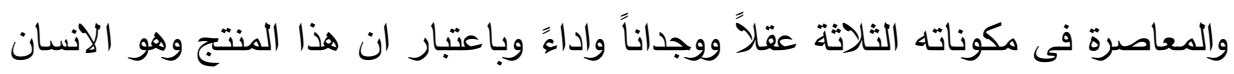
هو نقطة البداسة والوسط والنهاية فى تحقيق الجودة فى شتى مجالات الحياة فهو الكنز • المكنون

ويرى كل من توفيق مرعى، تحمد الحيلة ( . . . إ) ان التطوير عملية من عمليات

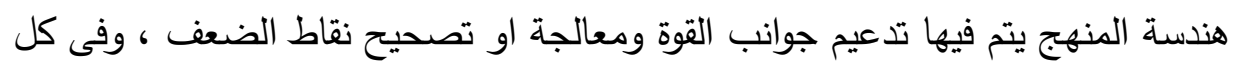
عنصر من عناصر المنهج، تصميماً وتقويماً وتتفيذاً، وفى كل عامل من العواملالمؤثرة فيه والمتصلة به، وفى كل اساس من اييه وفى ضوه معايير محددة . والتى تتعكس فى قدرته على إثباع حاجات صريحة أو ضمنية ( عماد أبوالرب وأخرون $(r \cdot 1 \cdot 6$ ويشير (Sowell,1996) الى ان عملية تطوير المنهج يجب ان تراعى عناصر المنهج بشكل متكامل، اي تراعى:

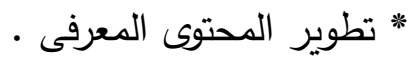

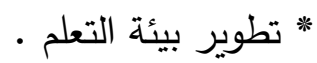

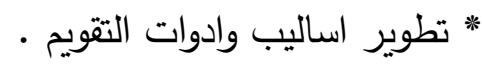
* تطوير فلسفة المنهج واهدافه.

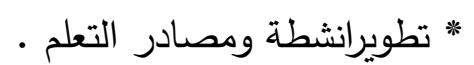
* تطويرطرائق التدريس ق ت 


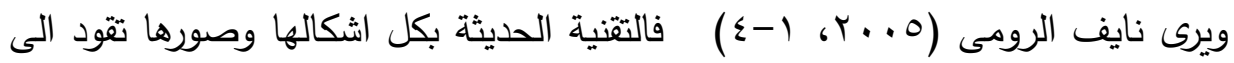
عالم غير عالمنا الذى نعيشة اليوم، وستتبدل وتتغير مفاهيم كثيرة وسيحل محلها مفاهيم جديدة وينبغى الاستعداد والتخطيط لها قبل ان نستيقظ فنجد انفسنا لا نستطيع ان نتاقلم

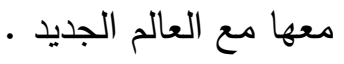

وقد تم الإستفاده من هذا المحور فى البحث الحالى فى تصميم استبانه للبحث وفقاً

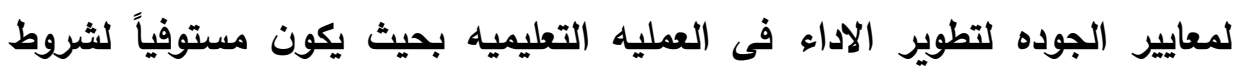
ومواصفات الجوده الأصليه القياسيه من حيث المعارف والمهارات والوجدان. لاراسات السابقة :

$$
\begin{aligned}
& \text { 1- دراسة(نورة الهزانى ، ب ا • r ) ): } \\
& \text { تهدف هذه الدراسة: }
\end{aligned}
$$

- التعرف إلى واقع طالبات التربية فى جامعة الملك سعود للشبكات الاجتماعية فى لـ

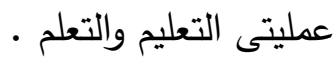

$$
\text { وأظهرت نتائج الدراسة : }
$$

- أن 0.V. من وجد أن الشبكات الاجتماعية ساهمت لديهم فى إثراء الحصيلة

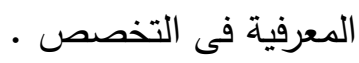

- - أجمعت NV \% على مدى أهمية الشبكات الاجتماعية فى التواصل وتكوين مجموعات

$$
\text { بحثية وعملية. }
$$

$$
\begin{aligned}
& \text { r- دراسة(رقية العلوانى ، ب ا •r ): } \\
& \text { تهدف هذه الدراسة: }
\end{aligned}
$$

- - تدريس العلوم الغسلامية فى الجامعات باستخدام التعليم الإكترونى -

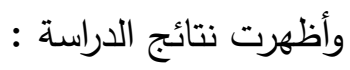

- ربط الطلبة بالواقع المعاصر وتدريهه على استعمال التقنيات الحديثة باتت لا غنى للدارس عنها ، وساهمت فى زيادة وتشجيع إطلاع الطلبة .

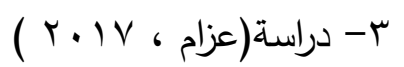


تهدف هذه الدراسة:

- قياس درجة استخدام الهواتف الذكية فى العملية التعليمية

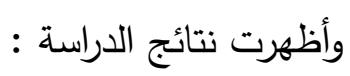

- أن درجة استخدام طلبة تكنولوجيا التعليم بالجامعات الأردنية فى التعليم كانت

$$
\text { متوسطة . }
$$

ملخص الدراسات السابقة تعدد الدراسات السابقة التي تتاولت متغيرات البحث

$$
\text { الحالى من زوايا مختلفة ، وقد اتفق }
$$

البحث الحالى مع معظم الدراسات من حيث يقدم البحث تصور عن استخدام التعلم

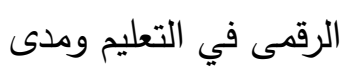

تحقيق جودة العملية التعليمية للطلبة ـ ولقد استفاد البحث الحالى من الدراسات

السابقة في بعض الجوانب منها بلورة مشكلة البحث، ، وتحديد أهداف البحث

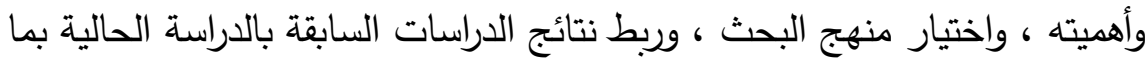

يحقق الترابط فى مجال البحث العلمى .

ثانياً:أداة الدراسة ومناقشة النتائج وتفسيرها .

إجراءات التجربة :

$$
\text { منهج البحث : }
$$

اعتمدت الباحثة المنهج الوصفي لمعالجة مشكلة هذا البحث نظراً لملائمته لطبيعة المشكلة،

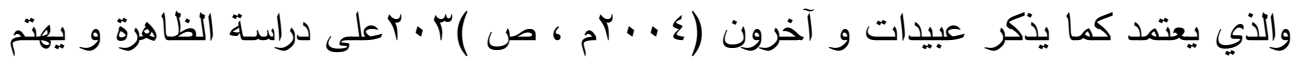
بالواقع ويهتم بوصفها وصفاً دقيقاً وواضحاً، ويعبر عنها كيفياً أو كمياً، ويعتبر هذا لهن المنهج هو المنهج المناسب للدراسة الحالية التي سعت الباحثة فيها إلى معرفة التعليم الرقمى وجودة العملية التعليمية من وجهة نظر الطلاب بجامعة المنوفية فى زمن الكورونا فى كليات -

جامعة المنوفية

rI.

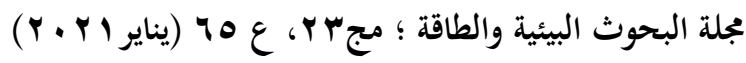




\section{1 - عينة الاراسة :}

تكونت عينة الدراسة من طلبة كليات- جامعة المنوفية وبلغ عددهم ( . .^) طالب ، وتم أخذ العينات عشوائياً.

\section{r- أدوات الدراسة : إعدادها وضبطها:}

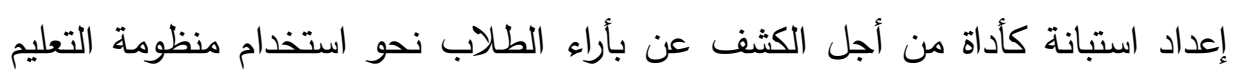

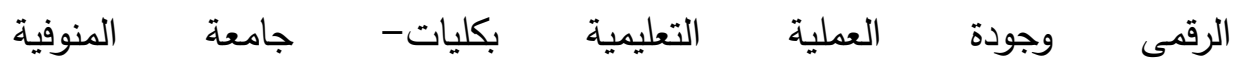
تكونت الاستبانة من جزأين: الروني 1- الجزء الأول :يرتبط بأراء الطلاب نحو استخدام منظومة التعليم الرقىى وجودة

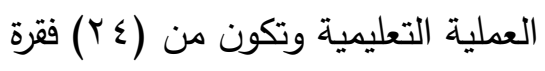
r- الجزء الثاني :يرتبط بمعوقات تطبيق التعليم الرقمى فى العملية التعليمية وتكون من (lV) فقرة.

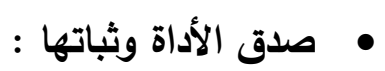

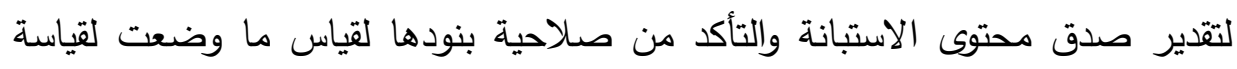

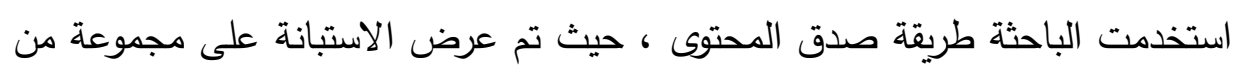

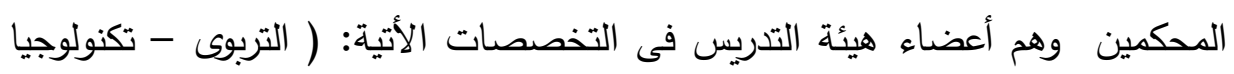

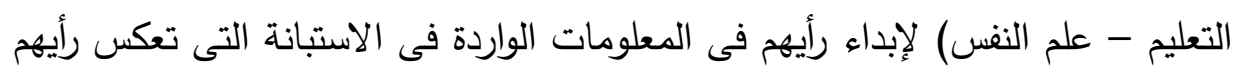

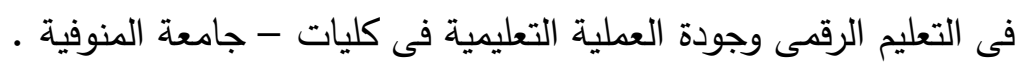

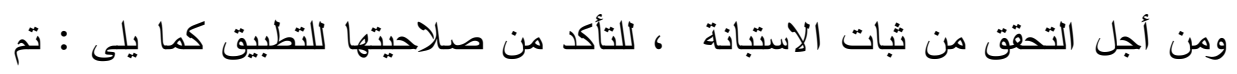

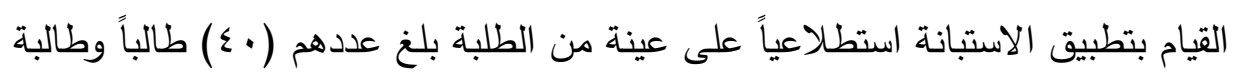

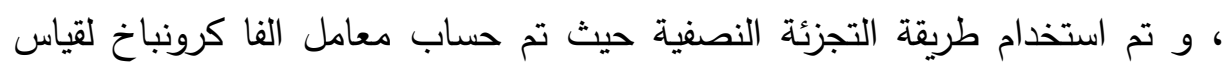

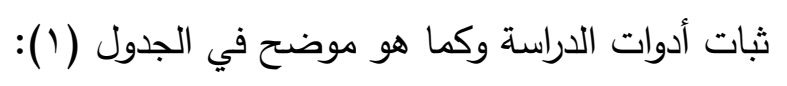

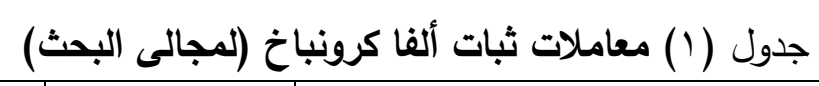

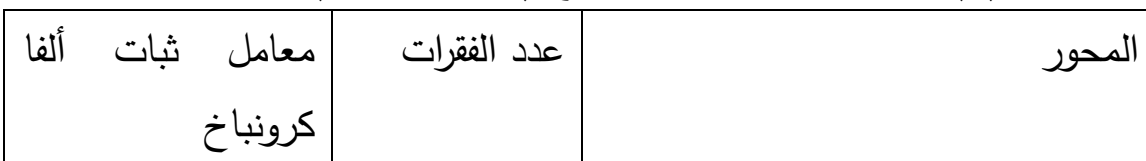


التعليم الرقمى وجودة العملية التعليمية من وجهة نظر طلاب جامعة المنوفية فى زمن جائحة كورونـا

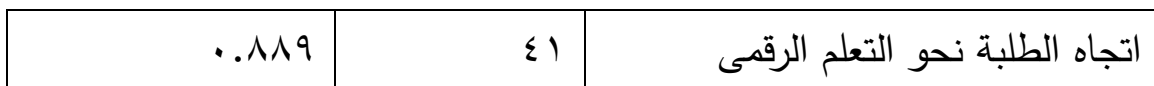

يتضح من الجدول رقم(1) أن معامل الثبات لمحاور الاستبانة، عال حيث بلغ معامل

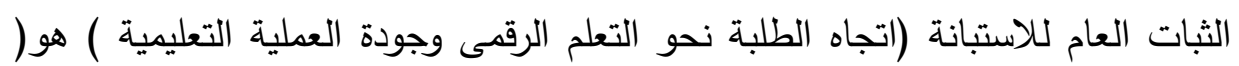

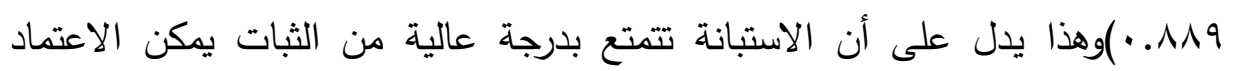
عليها.

\section{نتائج البحث ومناقشتها:}

النتائج المتعلقة بالسؤال الأول: أثر التعليم الرقمى على جودة العملية التعليمية من وجهة

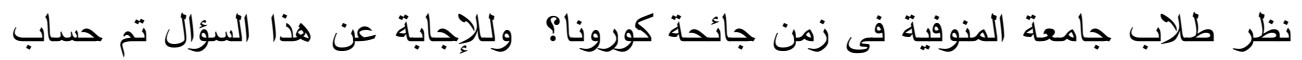

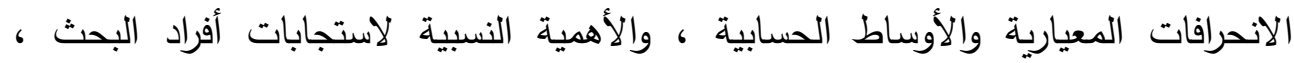

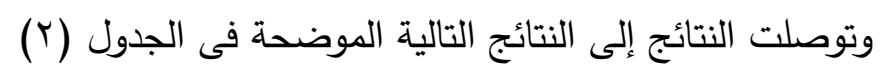

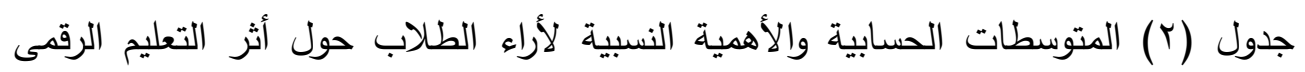
على جودة العملية التعليمية: - ملية

\begin{tabular}{|c|c|c|c|c|}
\hline الأهمية & المتوبط & الانحراف & الفقرة & المسلسل \\
\hline$\% \wedge$. & $\varepsilon \ldots+1$ & 1.14 & 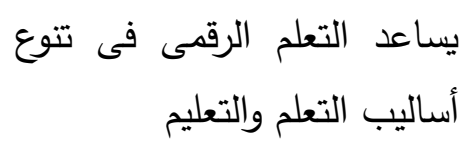 & 1 \\
\hline$\% \vee q$ & $r .90$ & $1 . r 0$ & الحكتسب الطلاب المعلومات & r \\
\hline 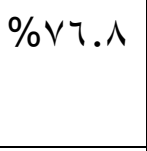 & 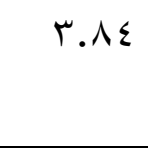 &.$A r$ & يعتبر التعلم الرقمى متع & r \\
\hline$\% \vee 0$ & r.vo & .90 & توفر مصادر متتوعة للحصول & $\varepsilon$ \\
\hline
\end{tabular}

YIY

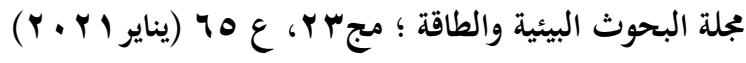


أ.د/ هيام مصطفى عبدالله سالم

\begin{tabular}{|c|c|c|c|c|}
\hline$\% \vee r$ & r. . &.$\wedge$ & من المجاعد على استكشاف العديد & 0 \\
\hline$\% \vee \vee . \wedge$ & r.人9 & 1.90 & 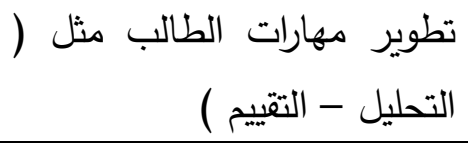 & 7 \\
\hline$\% 77$ & 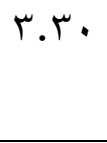 & 1.97 & عند الطهى مهارات التفكير الإبداعى & V \\
\hline$\% \vee r$ & r.7. & 1.19 & يساهم فى تطوير أداء المعلم & $\Lambda$ \\
\hline$\% \vee \cdot . \wedge$ & r.os & 1.1 & 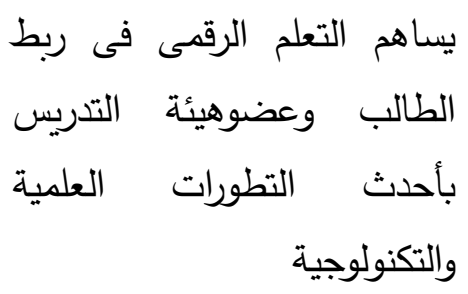 & 9 \\
\hline$\% 7 \vee . \varepsilon$ & 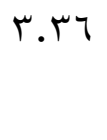 &. .99 & يساعد الطلاب على قبول & 1. \\
\hline$\% 77$ & 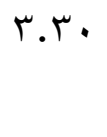 & 1.97 & 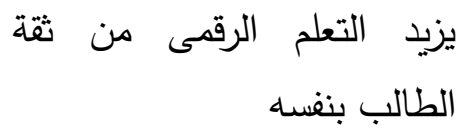 & 11 \\
\hline$\% \circ 9$ & $r .90$ &..$\wedge \wedge$ & تبادل الخبرات بين الطلاب & 1 \\
\hline$\% \vee r$ & 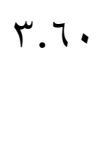 &.$\wedge$ & الذاتى وفقع التعلم الرقمى على التعلم & r \\
\hline$\% \vee 9$ & r.90 & $1 . \cdot \varepsilon$ & ينوع فى أساليب التقويم & $1 \varepsilon$ \\
\hline$\% \vee \leq$ & r.v. & 1.11 & 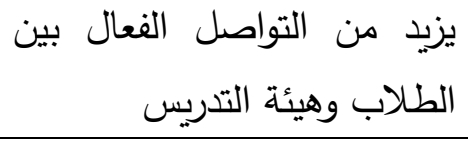 & 10 \\
\hline$\% \vee r$ & 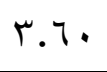 &.$\wedge$ & يوضح الأفكار من خلال & 17 \\
\hline
\end{tabular}

$r \mid r$

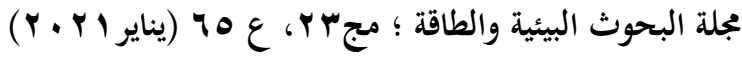


التعليم الرقمى وجودة العملية التعليمية من وجهة نظر طلاب جامعة المنوفية فى زمن جائحة كورونـا

\begin{tabular}{|c|c|c|c|c|}
\hline & & & الحوار والمناقشة & \\
\hline \multirow[t]{2}{*}{$\%$} & r.l. & $1 . r \cdot$ & تتمية دهارات التفكير الناقد لدى & iv \\
\hline & & & يتحول دور عضو & 11 \\
\hline$\% \wedge 1.7$ & $\varepsilon .1$ &.$V 0$ & عكان تقيد الطلاب بوقت أو & 19 \\
\hline$\% 79$ & r. $\leqslant 7$ & I.Y & يساعد عضى هيئة التدريس & $r$. \\
\hline$\% 71$ & r. o & 1.111 & الفرعى التعلم الرقمى الفروق بين الطلاب & YI \\
\hline$\% \vee \cdot . \Lambda$ & r.os & 1.9 & تعريف الطلاب بنواتج التعلم & $r r$ \\
\hline$\% \wedge$. & $\varepsilon .+1$ & 1.14 & يركز على الطالب المستهدف & 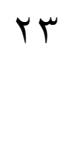 \\
\hline$\% \wedge r . r$ & $\varepsilon .11$ &.$v 7$ & للتعلح الطلاب التغذية الراجعة & $r \leqslant$ \\
\hline
\end{tabular}

نلاحظ من الجدول (Y) أن جميع الأراء كانت إيجابية وبشكل متوسط ، حيث تراوحت

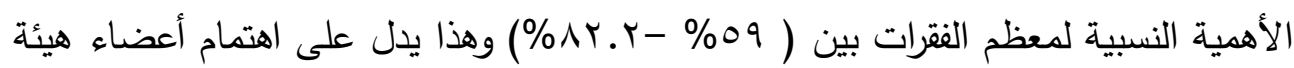
التدريس بتطبيق وتوظيف منظومة التعلم الرقمى فى العملية التعليمية فى ظل جائحة كورونا المستجدة ، كما يدل على اطلاع وتدريب أعضاء هيئة التدريس على التكنولوجيا الحديثة فى ولى لتى التدريس لتحقيق النتائج التعليمية المستهدفة من المقررات الدراسية الخاصة بالبرامج المختلفة. 
وتم ترتيب الفقرات ترتيبا تصاعديا حيث حلت بالمرتبة الأولى الفقرة (يمنح الطلاب التغذية

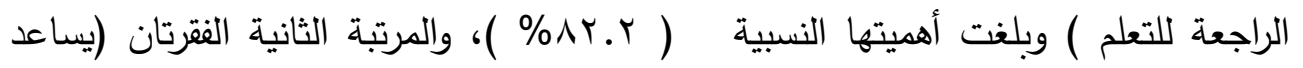
التعلم الرقمى فى تتوع أساليب التعلم والتعليم)،( يركز على الطالب المستهدف من العملية

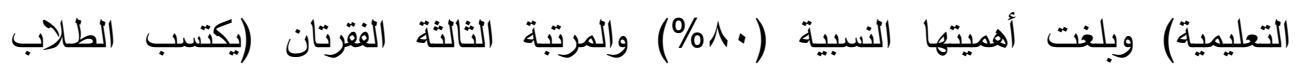

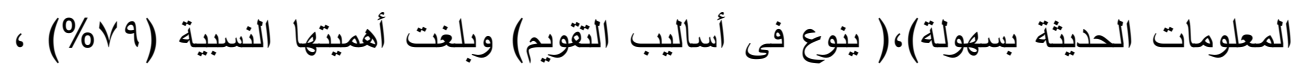
والمرتبة الرابعة الفقرة (تطوير مهارات الطالب مثل ( التحليل - التقييم ) وبلغت أهميتها

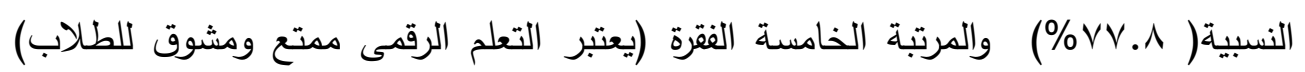

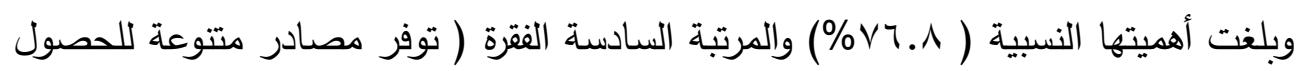

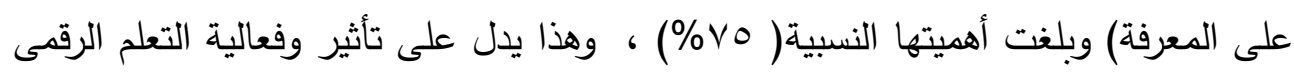

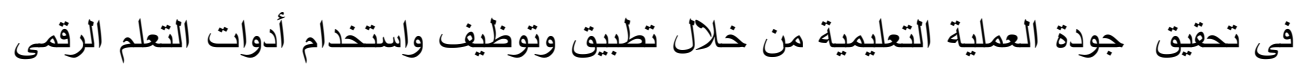
عبر الويب والاستفادة من كافة المصادر الإكترونية المتاحة عبر الويب ، كما أنها تتطلب وني من عضو هيئة التدريس أن يلعب أدواراً تختلف عن الدور التقليدى ، حيث أصبح دوره يرتكز على تخطيط العملية التعليمية وتصميمها وإعدادها بالإضافة إلى كونه أصبح مشرفاً

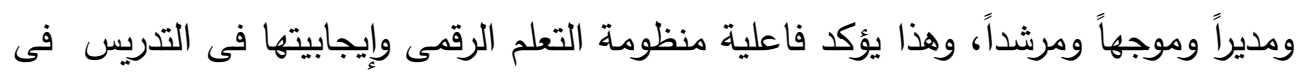

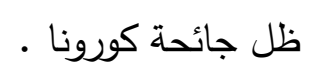
وأما أقل الفقرات كانت( تبادل الخبرات بين الطلاب وعضوهيئة التدريس بالكليات المناظرة) وبلغت أهميتها النسبية( \%09\%) وقد يرجع ذلك إلأى عدم وجود منظومة إدارية الكترونية

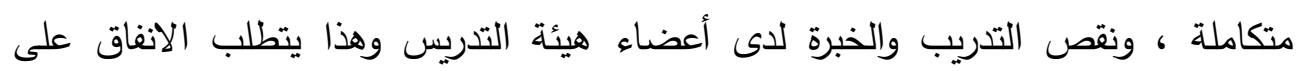
التدريب وتجهيز منظومة إدارية الكترونية متكاملة لجميع الكليات بالجامعة. النتائج المتعلقة بالسؤال الثانى : ما معوقات تطبيق التعليم الرقمى من وجهة نظر الطلاب

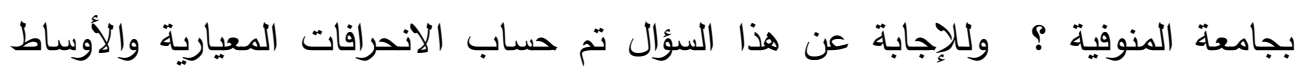
الحسابية ، والأهمية النسبية لفقرات الاستبانة ، وتوصلت هلت النتائج إلى النتائج التالية

الموضحة فى الجدول (r) 
التعليم الرقمى وجودة العملية التعليمية من وجهة نظر طلاب جامعة المنوفية فى زمن جائحة كورونا

جدول (r) المتوسطات الحسابية والأهمية النسبية لمعوقات تطبيق التعليم الرقمى فى العملية

\begin{tabular}{|c|c|c|c|c|}
\hline الأهمية النسبية & الوسط & الإنحراف & الفقرة & المسلسل \\
\hline$\% \wedge 0$ & E. Yo & r. & لأعضاء شبكة إنترنت متاحة دائما & 1 \\
\hline וr\% & 1.00 &. .10 & تشجيع الطلاب على التواصل & $r$ \\
\hline$\% \varepsilon$. & $r$ & $1 . r \wedge$ & تستخدم الفيديو والتسجيلات فى & r \\
\hline$\% \circ \wedge$ & $r .9$. & 1.7. & تلتواصتخ م البريد $\quad$ الإكترونى & $\varepsilon$ \\
\hline \%VY. & r. r. & $1 . .0$ & توجد قاعات مخصصة فى للتعلية الألكترونى & 0 \\
\hline וr\% & 1.00 &..$\vee 0$ & تالحسن بهاسوب باستمرار & 7 \\
\hline$\% \wedge r . \varepsilon$ & $\varepsilon .1 T$ & .911 & صعوبة الوصول إلى موقع & V \\
\hline$\% \leq \varepsilon$ & $r . r$. & $1 . V Y$ & كافى من أجهزة الحاسل يحتوى على عدد الألى & $\Lambda$ \\
\hline$\% \vee$. & . & I.YY & توظم توافر التدريب المناسب & 9 \\
\hline
\end{tabular}

Y 19

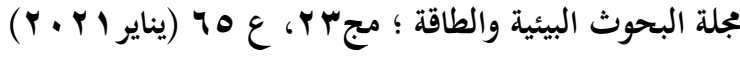


أ.د/ هيام مصطقى عبدالله سالم

\begin{tabular}{|c|c|c|c|c|}
\hline & & & بلة التع & \\
\hline$\% \wedge 1.7$ & $\varepsilon . \wedge$ & 1.11 & الخلل المتكرر للشبكة يعرق & $1 \cdot$ \\
\hline$\% \varepsilon$. & $r$ & $1 . Y \wedge$ & سب شخصى & 11 \\
\hline$\% \vee 0$ & o &. .19 & صعوبة القراءة على شاشة & Ir \\
\hline$\% \vee 7$ & r.人. &. .90 & قلة تشجيع أعضاء هيئة & 1r \\
\hline$\% \vee \varepsilon$ & r.V. &. .97 & عدم الشعور بالمسئولية ن & $1 \varepsilon$ \\
\hline \%VY. $\varepsilon$ & r. & 1.0 & عدم الوعى التكنولوجى للطلاب & 10 \\
\hline$\% \wedge \wedge$ & $\varepsilon . \varepsilon$. & 1.99 & صعوبة الاتصال مع شبكة & 17 \\
\hline \multirow[t]{3}{*}{$\% \wedge \wedge$} & $\varepsilon . \varepsilon$ & 1.99 & ضعف البنية التحتية فى & $1 \mathrm{~V}$ \\
\hline & & & الكليات من حيث ( الاتصالات & \\
\hline & & & 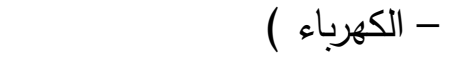 & \\
\hline
\end{tabular}

نلاحظ من الجدول (r) أن المعوقات التى ذكرت فى الجدول تؤثر وبشكل متوسط على تطبيق وتوظيف التعلم الرقمى فى العملية التعليمية ، حيث تراوحت الأهمية النسبية لمعظم

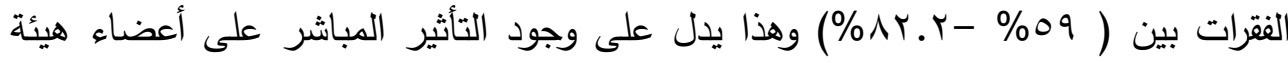
التدريس والطلاب ، ويقلل من إمكانية تفعيلة وتوظيفة بشكل أكثر لتحقيق النتائج التعليمية 
المستهدفة ، وكانت أعلى الفقرات والتى تشكل معيق كبير لتطبيق وتوظيف التعلم الرقمى

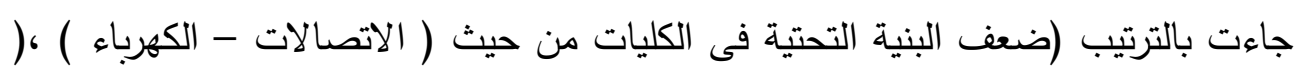

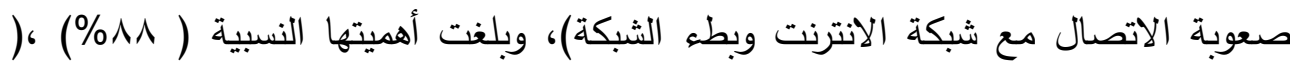
توجد شبكة إنترنت متاحة دائما لأعضاء هيئة التدريس فى الكلية) وبلغت أهميتها النسبية (1^0\%) ، (صعوبة الوصول إلى موقع الجامعة فى المناطق البعيدة) وبلغت أهميتها النسبية

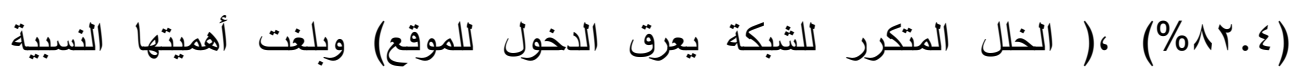

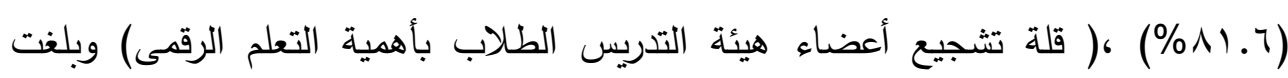

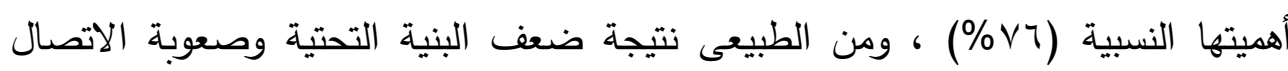
بالانترنت تشكل صعوبة على عضو هيئة التدريس فى تفعيل وإشراك جميع الطلاب

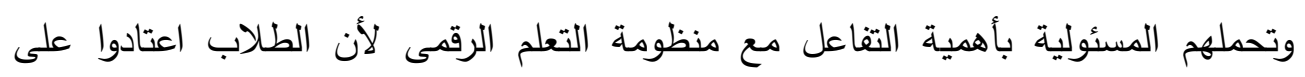

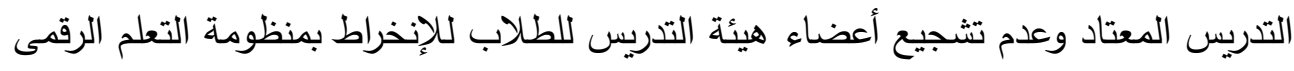
، وعدم توافر التدريب المناسب لأعضاء هيئة التدريس حول كيفية توظيف منظومة التعلم الرقمى فى العملية التعليمية. وفى الدرجة الاخيرة من المعيقات (تشجيع الطلاب على التواصل وتبادل الخبرات)،( تحسن

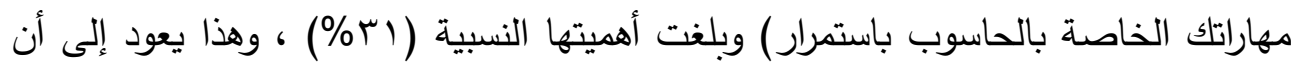
غالبية الطلاب وأعضاء هيئة التدريس فى أغلب الكليات بالجامعة قد تم التحاقهم بدورات تدريبية فى مجال استخدام الحاسوب وتكنولوجيا المعلومات اللازمة لإدارة عملية التعلم الرقمى بفاعلية لتحقيق جودة العملية التعليمية . التوصيات: - توفير بنية تحتية تعمل بشكل جيد ومتاحة لجميع أعضاء هيئة التدريس والطلاب فى كل كلية من الكليات - توفير فرص التدريب المناسبة لأعضاء هيئة التدريس وطلاب الجامعة على استخدام

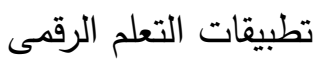


- عقد دورات وورش عمل متخصصة لإكساب أعضاء هيئة التدريس مهارات تصميم الدروس باستخدام منظومة التعلم الرقمى

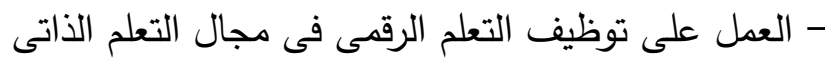
- تزويد الكليات بجميع البرمجيات التعليمية الحديثة والتى تساعدهم على توظيف التعلم

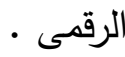
- إجراء المزيد من الدراسات والأبحاث على مؤسسات مختلفة لاستكمال الصورة الكلية حول فاعلية منظومة التعلم الرقمى وتحديد كافة المعيقات التى تواجه عملية تتفيذ هذه المنظومة.

\section{المراجع}

ا - احمد احمد (ץ . . Y). الجودة الشاملة فى الادارة التعليمية والمدرسية. الاسكندرية: دار

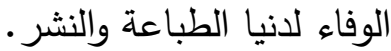

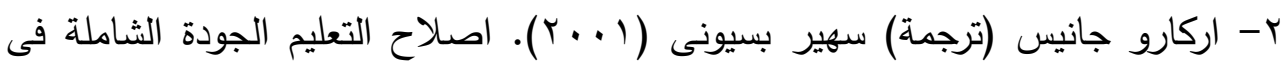
حجرة الدراسة. القاهره: دار الاحمدى للنشر.

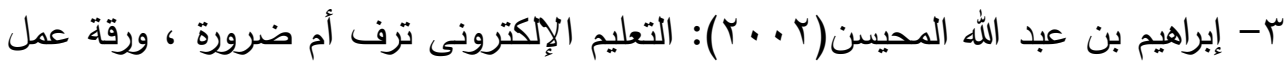

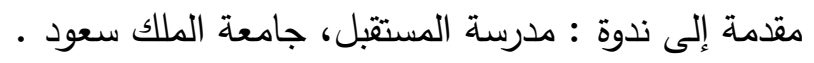

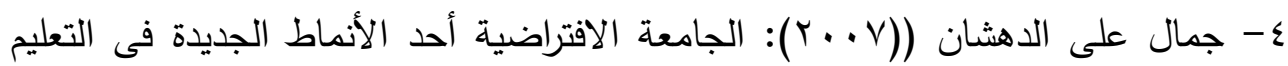

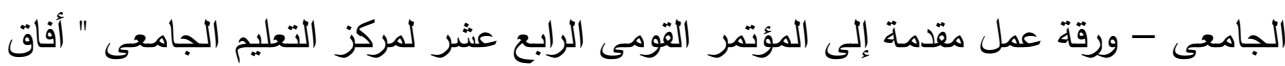
جديدة فى التعليم الجامعى العربى " فى هץ- بץ- نوفمبر ، دار الضيافة بجامعة عين شمس.

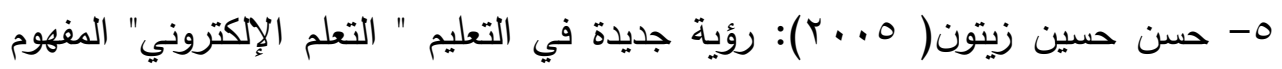

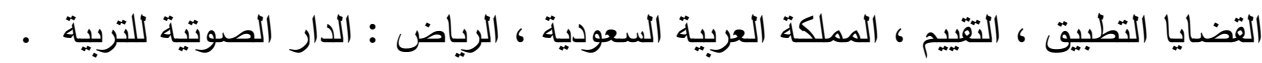

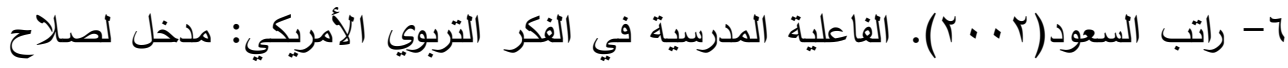
التعليم وتطويره في المدرسة العربية. مجلة دراسات: الجامعة الأردنية، المجلد اب(أ)، العدد 


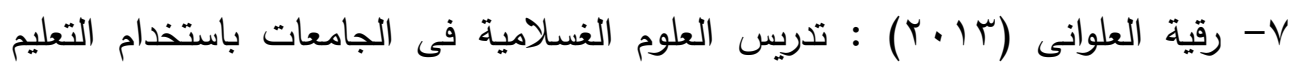
الإلكترونى ، مادة أحكام الاسرة نموذجاً ، المؤتمر الدولى الرابع للتعليم الألكترونى بالبحرين.

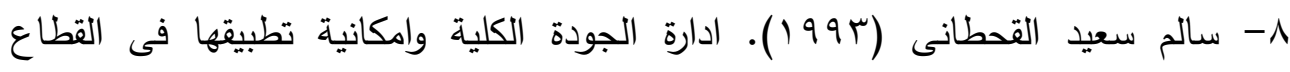

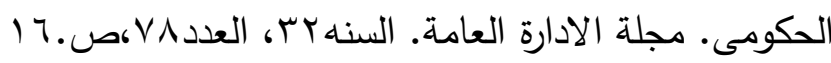

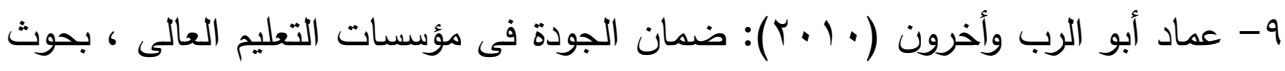

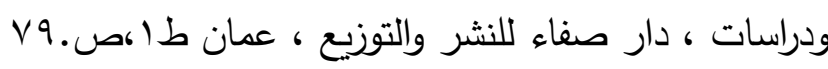
• 1- عبد الفتاح زين الدين (1997 (1). المنهج العلمى لتطبيق ادارة الجودة الثاملة فى ولى المؤسسات العربية. القاهرة: دار النهضة العربية. 1 ا- المجالس القومية المتخصصة( ع . . ץ). التمحور حول العالم فى الجامعات والمعاهد المصرية. الدورة الثلاثون. القاهره: المجلس القومى للتعليم والبحث العلمى والتكنولوجيا .

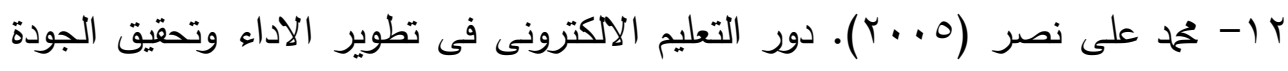

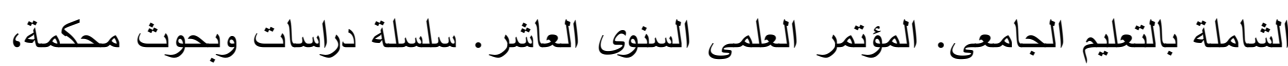

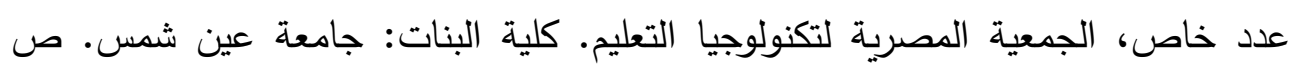

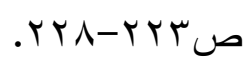
على ع ا - ححمد مجاهد، بديرالمتولى ( ؟ . ؟). الجودة والاعتماد فى التعليم الجامعى: مع التطبيق على كليات التربية. القاهرة: المكتبة العصرية للنشر والتوزيع. 10 - نايف هاشل الرومى (0 . . ب). ثورة المعرفة وتحدى التقنية: المدرسة بوابة المستقبل لمجتمع جديد. من بحوث الندوة الاقليمية حول تطوير التعليم ما بعد الاساسى للدول العربية

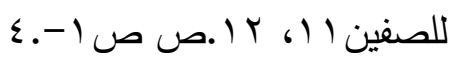
7 ا- نورة الهزانى (T/ + ب):فاعلية الشبكات الغجتماعية الغلكترونية فى تطوير عملية التعليم والتعلم لدى طالبات كلية التربية فى جامعة الملك سعود ، المجلة الدولية للأبحاث التربوية. 


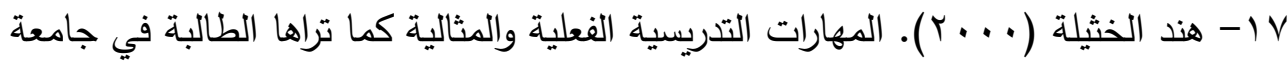
الملك سعود. مجلة جامعة أم القرى للعلوم التربوية والإجتماعية والانسانية. المجلد با. ال.

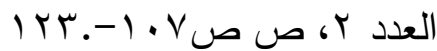

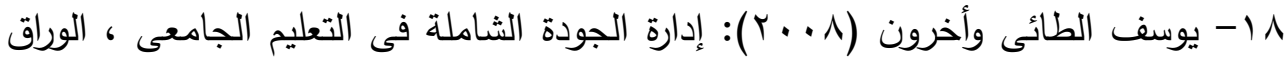

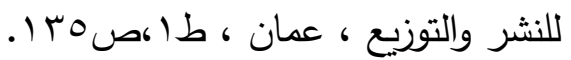
19-التعليم الرقمى ، تطبيقات واستراتيجيات والتعلم الالكترونى الحديث ، الموقع

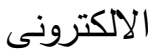
https://sites.google.com/site/learningandteachingstrategies $1 / \mathrm{h}$

20- Al-Karam; A. M. Al- Ali \& N. M.(2001). E- learning: the new breed of education.In Billeh, V. \& Ezzat, A.(Eds.), Education development through utilization of technology: UNESCO Regional Office for Education in the Arab States.pp. 49-63 21- Cheng Y.(1996). The Pursuit of School Effectiveness. The Hong Kong Institute of Educational Research . Hong Kong: The Chinese University. 22- Sally, M. ;Bill, C. ; William, H. (2009). Improving Workforce Capabilities with the $\mathrm{Ca}$-maturity model From www.Saly.W.C.com/Impr.Html 